\title{
Primary care approach to urinary tract infection in children
}

Jeanette Keng Wein $\underline{\operatorname{Tan}}^{1}$, MMed, MrCPCHuk, Joanne Mui Ching $\underline{\operatorname{Tan}}^{1}$, MMed, MRCPCHUK, Choon How $\underline{H o w}^{2}$, MMed, FCFP,

Esther Hui Min Leow ${ }^{3}$, MMed, MRCPCHUK

\begin{abstract}
Jane, a seven-month old Chinese girl, was taken to your clinic for a high fever $\left(39.6^{\circ} \mathrm{C}\right)$ of two days' duration for no apparent reason. Jane was born full-term with a birth weight of 2,800 g. Her mother had reported during her postnatal visits that she was coping well. Jane was her first child. However, her mother said that Jane had been refusing her cereals for the past two days and was now taking only half her usual milk portions. On direct questioning, she reported that Jane's diapers were not as heavy as usual, and her urine had a stronger smell. No blood was noted. Jane seemed more tired but was still interested in playing with her toys about an hour after taking syrup paracetamol self-administered by her mother. On examination, Jane was febrile at $38.9^{\circ} \mathrm{C}$. Her vital signs were stable, her tongue was moist and she had good skin turgor. She was fretful but consolable when carried by her mother. A head-to-toe examination did not reveal any localising signs of infection.
\end{abstract}

\section{WHAT IS URINARY TRACT INFECTION?}

Urinary tract infection (UTI) is defined as the presence of pathogenic micro-organisms in the urinary tract, resulting in a symptomatic inflammatory response, usually evidenced by pyuria. ${ }^{(1)}$ Lower UTI (otherwise known as cystitis) is isolated to the bladder and is the most common form of UTI. Children with lower UTI tend to present with lower tract symptoms, including frequency, urgency, dysuria, and suprapubic pain and tenderness. Upper UTI involves the renal parenchyma, causing acute pyelonephritis (APN). The majority of febrile UTIs in infants and young children are upper UTIs.

Defining the location of the UTI (i.e upper or lower) or as complicated versus uncomplicated is useful in determining prognosis, treatment and follow-up. ${ }^{(1)}$ Complicated UTI involves risk factors that are summarised in Box 1.

Other features of atypical or complicated UTI include patients who: have a history of previous UTI; are septic or who have a disease that is more severe than usual; have poor urine output or raised creatinine; have a palpable abdominal mass/ bladder; fail to respond to appropriate treatment; or have atypical pathogens. ${ }^{(2)}$

\section{HOW RELEVANT IS THIS TO MY PRACTICE?}

UTI is one of the most common bacterial infections seen in children and a leading cause of acute sepsis in infants requiring hospitalisation. It is most common in the first year of life, with a higher incidence in boys compared to girls, in those aged below six months. By seven years of age, $8.4 \%$ of girls and $1.7 \%$ of boys would have had one or more symptomatic UTIs. ${ }^{(3)}$ UTI carries an acute risk of morbidity and mortality due to urosepsis, renal abscess formation and acute kidney injury. Acquired renal scars can lead to chronic renal insufficiency, proteinuria and hypertension subsequently in adulthood. Different studies show widely varying results on renal scarring following UTI, ranging from $10 \%$ to $40 \%$. $^{(4-6)}$

Fever in a young child is a common presentation in primary care. As UTIs commonly present with acute undifferentiated fever, especially in a pre-verbal child, it is important that firstline healthcare providers appropriately diagnose and treat UTIS in children promptly, given their immediate complications as well as potential for permanent renal damage with considerable sequelae.

\section{WHAT CAN I DO IN MY PRACTICE?}

Recognising and treating UTIs promptly and accurately is important. Due to the non-specificity of symptoms of UTI in young children, screening for UTI should be done early via urine investigations, especially in the absence of an obvious source of infection. A properly collected urine sample should be sent for culture before starting treatment. Fig. 1 shows a flowchart for diagnosing UTI.

\section{History and physical examination \\ Clinical signs and symptoms of a UTI depend on the age of the child, location of the UTI (upper or lower UTI) and severity of the illness. Fever is not a feature in lower UTIs, which tend to present with local or voiding symptoms such as dysuria, frequency,}

${ }^{1}$ Department of Paediatrics, KK Women's and Children's Hospital, ${ }^{2}$ Care and Health Integration, Changi General Hospital, ${ }^{3}$ Department of Nephrology, KK Women's and Children's Hospital, Singapore

Correspondence: Dr Jeanette Keng Wein Tan, Consultant, Department of General Paediatrics, KK Women's and Children's Hospital, 100 Bukit Timah Rd, Singapore 229899. jeanette.tan.k.w@singhealth.com.sg 


\begin{tabular}{l}
\hline Box 1. Risk factors for urinary tract infection: \\
- Bowel and bladder dysfunction \\
- Constipation \\
- Voiding postponement \\
- Urinary tract abnormalities \\
- Neurogenic bladder \\
- Vesicoureteric reflux \\
- Posterior urethral valve \\
- Prune belly syndrome \\
- Ureteropelvis/ureterovesical junction obstruction \\
- Megaureter \\
- Duplex kidney \\
- Polycystic kidney disease \\
- Dysplastic kidney disease \\
- Indwelling catheter/stents surgically placed within the urinary tract \\
- Immunosuppressed states \\
- Boys who are uncircumcised \\
- Kidney/bladder stones
\end{tabular}

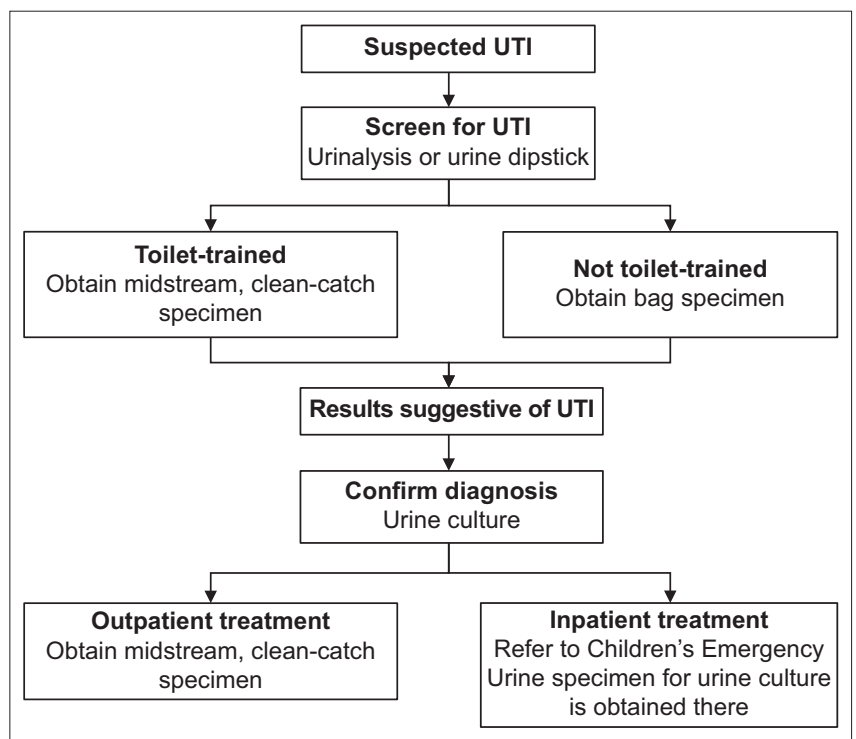

Fig. 1. Flowchart shows workflow for diagnosing urinary tract infection (UTI).

urgency and suprapubic pain. Important points in history taking and physical examination are summarised in Tables I and II, respectively.

The cardinal symptom of APN is high fever without an obvious source of infection, often with chills and rigors. Neonates often present with very non-specific symptoms such as unexplained fever (may be low grade), lethargy, irritability, vomiting or poor feeding. Less commonly, they can present with late-onset/prolonged jaundice or faltering growth. Screening for UTI is part of the workup for neonates or infants with prolonged jaundice and failure to thrive. In pre-verbal infants and toddlers, the presentation is also likely to be non-specific, including unexplained fever, diarrhoea, vomiting, abdominal pain, foul-smelling urine or faltering growth. In older (verbal) children and adolescents, symptoms and signs are more specific, including fever, dysuria, foul-smelling or cloudy urine, urgency, frequency, new-onset urinary incontinence, gross haematuria, abdominal or flank pain, and vomiting. According to guidelines from the American Academy of Pediatrics, factors that increase the likelihood of UTI include age of below 12 months, fever for more than 48 hours, no other apparent source of fever, and fever of or exceeding $39^{\circ} \mathrm{C} .{ }^{(7)}$

In history taking and physical examination, it is important to look for complications as well as predisposing factors for UTI. Acute complications include sepsis, renal abscess formation and acute kidney injury. A history of decreased urine output is significant and could be due to dehydration or acute kidney injury. On physical examination, physicians should look out for the child who has an ill appearance, is mottled, and has unstable vital signs (as tachycardia is the first sign of compensation in a child in shock) and decreased activity. Renal punch, usually performed in older children, may be positive in APN.

Predisposing factors of UTI in children include bowel and bladder dysfunction, urinary tract abnormalities, indwelling catheters, immunosuppressed status, being an uncircumcised boy, and a history of renal or bladder stones (Box 1). As part of history taking, it is important to ask about these risk factors, in particular antenatal history, including abnormal scans, drug history, a personal history of previous UTI and a family history of kidney problems. All children should have a thorough physical examination to look for findings that would suggest a complicated UTI. Palpation of the abdomen and pelvis is crucial, looking out for abnormal masses including ballotable kidneys, palpable fecal masses and a palpable bladder. A careful genitourinary examination should also be performed, assessing for abnormalities of the urethral opening, continuous dribbling of urine (which may be due to ectopic ureter), severe phimosis, balanitis, labial adhesions or vulvovaginitis. Examination of lower limb neurology and the spine is important. Signs of spinal dysraphism such as sacral dimples, subcutaneous lipomas, haemangioma, hyper- or hypopigmentation, and hair tufts may indicate occult spinal lesions.

The term bowel and bladder dysfunction is used to describe the spectrum of lower urinary tract symptoms that accompany bowel disturbance in the form of constipation and/ or encopresis. It has been reported to be a key risk factor for recurrent UTIs in children. ${ }^{(8)}$ Bowel habits should be taken as part of history taking. Fecal masses may be noted on physical examination in a child with constipation. Other predisposing factors include inappropriate perineal hygiene, inadequate fluid intake, and infrequent or incomplete bladder emptying. In adolescent patients, it may be appropriate to ask for their sexual history.

\section{Investigations}

Urine culture is the gold standard for diagnosing UTI. ${ }^{(9)}$ In patients suspected of having a UTI, a screening urine dipstick test or urinalysis should be done. The technique for urine collection is primarily determined by whether the patient is toilet trained. In children who have not achieved urinary continence, this can be done using a urine bag. In toilettrained children and adolescents, midstream clean-catch urine 
Table I. Important aspects of history taking for children with UTI.

\begin{tabular}{|c|c|}
\hline Category & Signs and symptoms \\
\hline \multirow[t]{3}{*}{ Presenting complaint } & $\begin{array}{l}\text { Neonate } \\
\text { Common } \\
\text { - Unexplained fever } \\
\text { - Lethargy } \\
\text { - Irritability } \\
\text { - Vomiting } \\
\text { - Poor feeding } \\
\text { Less common } \\
\text { - Late-onset/prolonged jaundice } \\
\text { - Faltering growth }\end{array}$ \\
\hline & $\begin{array}{l}\text { Preverbal toddlers/young children } \\
\text { - Unexplained fever } \\
\text { - Diarrhoea } \\
\text { - Vomiting } \\
\text { - Abdominal pain } \\
\text { - Foul-smelling urine } \\
\text { - Faltering growth }\end{array}$ \\
\hline & $\begin{array}{l}\text { Verbal older children/adolescent } \\
\text { - Fever } \\
\text { - Foul-smelling or cloudy urine } \\
\text { - Dysuria } \\
\text { - Urgency } \\
\text { - Frequency } \\
\text { - New-onset urinary incontinence } \\
\text { - Gross haematuria } \\
\text { - Abdominal/flank pain } \\
\text { - Vomiting }\end{array}$ \\
\hline Complication & $\begin{array}{l}\text { - Decreased activity } \\
\text { - Decreased urine output }\end{array}$ \\
\hline \multirow[t]{5}{*}{ Predisposing factor } & $\begin{array}{l}\text { Antenatal history } \\
\text { Scans }\end{array}$ \\
\hline & $\begin{array}{l}\text { Past medical history } \\
\text { - Previous UTI } \\
\text { - Urinary tract abnormalities } \\
\text { - Indwelling catheters } \\
\text { - Boys who are uncircumcised }\end{array}$ \\
\hline & $\begin{array}{l}\text { Family history } \\
\text { Kidney problems }\end{array}$ \\
\hline & $\begin{array}{l}\text { Systemic review } \\
\text { - Bowel habits } \\
\text { - Toilet trained } \\
\text { - Perineal hygiene } \\
\text { - Sexual history (in adolescents) }\end{array}$ \\
\hline & $\begin{array}{l}\text { Drug history } \\
\text { - Immunosuppressed states } \\
\text { - Pre-treatment with antibiotics (impact on } \\
\text { urine culture interpretation) }\end{array}$ \\
\hline
\end{tabular}

UTI: urinary tract infection

samples should be collected. If the results are suggestive of UTI with the presence of pyuria and/or nitrites, a properly collected urine sample should be sent for culture before starting treatment. If the child is clinically unwell, he/she should be referred to the emergency department, where urine specimens may be collected via catheterisation. If the child
Table II. Important aspects of physical examination for children with urinary tract infection.

\begin{tabular}{|ll|}
\hline System & Findings \\
\hline General & - Vital signs, including blood pressure \\
& - Hydration status \\
& - Growth parameters \\
& - Dysmorphism \\
\hline Abdomen & - Ballotable kidney \\
& - Palpable bladder \\
& - Masses, including fecal masses \\
& - Renal punch \\
\hline Genitourinary system & - Abnormalities of the urethral opening \\
& - Phimosis \\
& - Genital adhesions \\
& - Vulvovaginitis \\
\hline Lower limbs & Neurological examination \\
\hline Spine & Spinal dysraphism \\
\hline
\end{tabular}

is otherwise stable, a clean-catch specimen may be obtained in the outpatient setting. As there can be a risk of culture contamination from clean-catch specimens, two separate specimens should ideally be obtained, with at least one specimen obtained prior to initiating antibiotics.

To collect a bagged specimen or midstream clean-catch specimen, the genitalia and perineum should be broadly cleaned with an antiseptic solution to decrease the rate of contamination (Figs. 2a and b). The toilet-trained child should urinate into a toilet or urinal. Midway through urination, a specimen should be collected into a sterile urine container. For the child who is not toilet-trained, diapers should be taken off and a midstream specimen collected opportunistically.

It is important to clearly label the method used for urine collection, as the diagnostic criteria may vary according to the method used (Table III). For urine culture, a fresh urine specimen is required. The specimen should ideally be collected and sent to the laboratory within two hours. If a container is given to parents to take home and collect the urine, proper instructions should be given regarding handling of the urine specimen and when to return with the specimen. The container should only be opened when they are about to collect the urine sample and closed immediately upon collection to minimise contamination. For the same reason, the inner surface of the container should not be touched. The midstream urine should be collected directly in the container.

Urine cultures should always be interpreted with clinical correlations. False positive urine culture can be due to contamination, while false negative results can be due to partial treatment or diluted urine. Up to $9 \%$ of patients with APN may have equivocal or negative urine culture results. ${ }^{(10)}$ If urine cultures are negative or equivocal but suspicion of UTI is high, repeat urine cultures should be sent and the child referred to a tertiary hospital for further imaging. Viruses, urinary schistosomiasis and funguria are differentials in children with an appropriate history of exposure and high suspicion of UTI but negative urine cultures. 

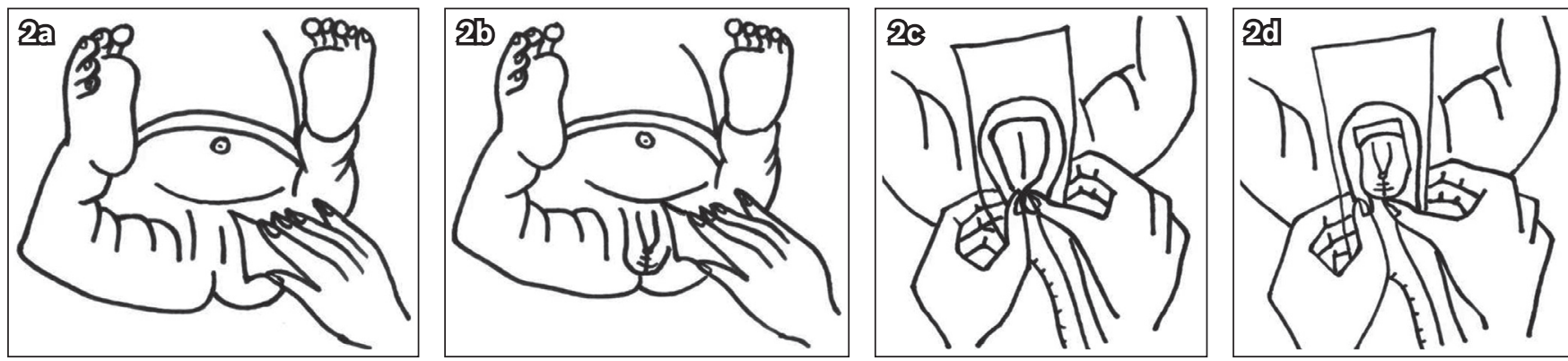

Fig. 2 Illustrations show the genitalia and perineum being cleaned with an antiseptic solution before obtaining a urine specimen. (a) For girls, the labia should be spread and the perineum cleansed 2-3 times with non-foaming antiseptic solution or mild soap. (b) For boys, the meatus should be cleansed 2-3 times with non-foaming antiseptic solution or mild soap. The foreskin should be retracted before cleansing for those who are uncircumcised. Ensure that the foreskin is reduced to its normal position so that a paraphimosis does not develop. (c \& d) A urine bag is applied by removing the backing from the adhesive and applying it over the vulva or penis and scrotum. The bag is regularly monitored and removed once urination has occurred.

Table III. Method of urine collection and interpretation.

\begin{tabular}{|c|c|c|}
\hline $\begin{array}{l}\text { Method of } \\
\text { collection }\end{array}$ & $\begin{array}{l}\text { Colony-forming } \\
\text { units } / \mathrm{mL}^{*}\end{array}$ & $\begin{array}{l}\text { Probability of } \\
\text { infection (\%) }\end{array}$ \\
\hline \multirow[t]{2}{*}{ Suprapubic tap } & $\begin{array}{l}\text { Gram-negative bacilli: } \\
\text { any count }\end{array}$ & $>99 \%$ \\
\hline & $\begin{array}{l}\text { Gram-positive cocci } \\
>1,000\end{array}$ & $>99 \%$ \\
\hline \multirow{4}{*}{$\begin{array}{l}\text { Transurethral } \\
\text { catheterisation }\end{array}$} & $>100,000$ & $95 \%$ \\
\hline & $>10,000-100,000$ & Infection likely \\
\hline & $1,000-10,000$ & $\begin{array}{l}\text { Doubtful, repeat if } \\
\text { indicated }\end{array}$ \\
\hline & $<1,000$ & Infection unlikely \\
\hline \multirow{4}{*}{$\begin{array}{l}\text { Midstream, clean- } \\
\text { catch }\end{array}$} & 2 specimens $>100,000$ & $90 \%$ \\
\hline & 1 specimen $>100,000$ & $80 \%$ \\
\hline & $50,000-100,000$ & $\begin{array}{l}\text { Doubtful, repeat if } \\
\text { indicated }\end{array}$ \\
\hline & $<50,000$ & Infection, unlikely \\
\hline $\begin{array}{l}\text { Mixed bacterial } \\
\text { growth }\end{array}$ & Contamination & \\
\hline
\end{tabular}

*Refers to pure growth.

\section{Treatment and follow-up}

Timely antibiotic treatment is the cornerstone of UTI treatment and paramount in minimising complications. Most UTIs are caused by Escherichia coli and other enteric Gram-negative organisms, the majority of which are sensitive to gentamicin or cephalosporins. In younger infants (particularly in those aged $<3$ months), Gram-positive cocci may cause UTI and thus ampicillin/amoxicillin may be added to cover for these organisms. ${ }^{(11)}$

Lower UTIs can be treated in outpatient settings with one week of oral antibiotics such as cephalexin or Bactrim, which is contraindicated in G6PD (glucose-6-phosphate dehydrogenase)deficient patients. ${ }^{(12)}$ Urine cultures should be actively traced to enable targeted antibiotic therapy, and the patient should be reviewed for resolution of symptoms.

Upper UTIs can be effectively treated with oral antibiotics in the outpatient setting for 14 days or inpatient with intravenous antibiotics, followed by oral therapy once the patient improves. ${ }^{(13)}$ The decision on outpatient or inpatient therapy

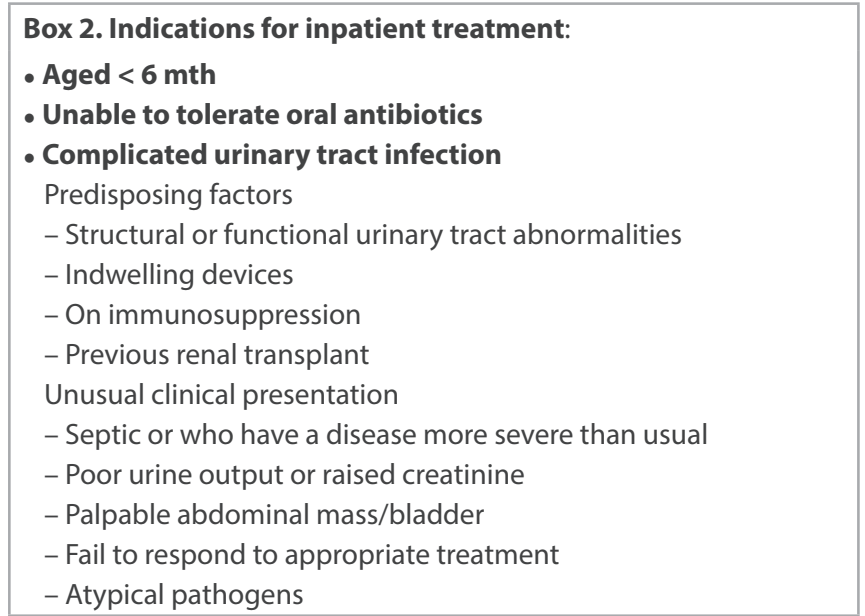

depends on a few factors. Inpatient parenteral therapy should be considered in acutely ill children, children who cannot tolerate oral therapy and those with complicated UTIs (Box 2). Internationally, there is no consensus on using age as a criterion for inpatient parental therapy. ${ }^{(1)}$ In general, babies younger than six months of age should be admitted for septic workup and intravenous antibiotics. Follow-up assessment to confirm an appropriate clinical response should be performed 48-72 hours after initiating antimicrobial therapy in all children with UTI. They should be referred to a tertiary hospital for intravenous antibiotics if they fail to respond to oral antibiotics. Table IV summarises the commonly used antibiotics for uncomplicated UTI. ${ }^{(13)}$

\section{Referring to a specialist}

As a general rule, all patients with one episode of febrile UTI (upper UTI) and patients who have recurrent cystitis should be referred to a specialist clinic for further evaluation, ideally 4-6 weeks after infection.

Renal and bladder ultrasonography is non-invasive and can be used to evaluate renal parenchyma, renal size and urinary tract anatomical abnormalities. It is recommended after the first febrile UTI. To avoid false positive studies, it is usually done after the UTI has been treated, because acute infection can alter the size and echogenicity of the renal parenchyma and cause transient hydronephrosis. ${ }^{(7)}$ Renal and bladder 


Table IV. Commonly used oral antibiotics and recommended dosing
for uncomplicated urinary tract infection (UTI).
\begin{tabular}{|lll|}
\hline Oral antibiotics & Dosage & Special considerations \\
\hline Cephalexin & $50 \mathrm{mg} / \mathrm{kg} /$ day q8h & Max dose $500 \mathrm{mg} / \mathrm{dose}$ \\
\hline Augmentin & $\begin{array}{l}50 \mathrm{mg} / \mathrm{kg} / \mathrm{day} \\
\text { (amoxicillin } \\
\text { component) } \mathrm{q} 12 \mathrm{~h}\end{array}$ & Max dose $1,000 \mathrm{mg} / \mathrm{dose}$ \\
\hline Co-trimoxazole* & $\begin{array}{l}8 \mathrm{mg} / \mathrm{kg} / \mathrm{day} \\
\text { (trimethoprim) } \\
\mathrm{q} 12 \mathrm{~h}\end{array}$ & $\begin{array}{l}\text { Max dose } 160 \mathrm{mg} / \text { dose } \\
\text { In children }>12 \text { year old, } \\
\text { 3 days of co-trimoxazole } \\
\text { can be considered for } \\
\text { treatment of lower UTI } \\
\text { instead of } 7 \text { days. }\end{array}$ \\
\hline Trimethoprim & $8 \mathrm{mg} / \mathrm{kg} / \mathrm{day} \mathrm{q} 12 \mathrm{~h}$ & $\begin{array}{l}\text { For patients with G6PD } \\
\text { deficiency who cannot } \\
\text { take co-trimoxazole due } \\
\text { to the sulfamethoxazole } \\
\text { component. }\end{array}$ \\
\hline
\end{tabular}

*Contraindicated in G6PD deficiency and in neonates. G6PD: glucose-6-phosphate dehydrogenase; q8h; every 8 hours; q12h: every 12 hours

ultrasonography may be performed during the acute infection to look for renal abscess or pyonephrosis in patients who fail to respond to appropriate treatment or whose illness is more severe than expected. Dimercaptosuccinic acid (DMSA) imaging is a nuclear imaging study used to identify alterations in radiotracer uptake within the renal parenchyma. It is done 4-6 months post infection and is the gold standard for diagnosing renal scars. Micturating cystourethrogram (MCU) is the gold standard for diagnosing vesicoureteric reflux (VUR). It also detects abnormalities of the lower urinary tract. Indications for an MCU generally include atypical or complicated UTI, abnormal renal and bladder ultrasonography, and recurrent UTI. ${ }^{(7)}$

\section{Secondary prevention}

The role of antibiotic prophylaxis in paediatric UTI prevention has been widely debated over the past few decades. In the past, antibiotic prophylaxis was used to reduce the risk of recurrent UTIs and the subsequent developmental of renal scarring, which may in turn lead to renal dysfunction. However, recent studies have shown that although antibiotic prophylaxis may reduce the incidence of recurrent $\mathrm{UTI}$, it did not reduce the risk of or protect against renal scarring. In addition, exposure to prophylactic antibiotics has been shown to increase the likelihood of resistant infections. ${ }^{(3)}$ Locally, in view of some benefits shown in select patient populations, we usually start antibiotics prophylaxis in patients at risk of recurrent UTI, including those with underlying urinary tract abnormalities.

Treatment of constipation with stool softeners has been shown to effectively prevent recurrent UTI in children without urinary tract anatomical abnormalities. ${ }^{(14)}$ Biofeedback training together with regular voiding has been successful in reducing recurrent UTIs in children with detrusor instability or other dysfunctional voiding. ${ }^{(15)}$
Routine circumcision in boys does not reduce the risk of UTI enough to justify the risk of surgical complications. However, it may considered for boys who have recurrent UTI or highgrade VUR in whom circumcision may be clinically beneficial. ${ }^{(16)}$

Other prophylactic therapies using methenamine, cranberry juice and probiotics have been evaluated in comprehensive studies and found to have insufficient evidence to support the use of such agents as prevention. ${ }^{(17-19)}$

\section{TAKE HOME MESSAGES}

1. The majority of febrile UTIs in infants and young children are upper UTIs, which carry a $10 \%-40 \%$ risk of renal scarring.

2. Upper UTIs predominantly present with high fever, with or without other symptoms such as vomiting and irritability, whereas lower UTIs usually present with urinary symptoms such as dysuria, urgency and frequency in an otherwise afebrile, well child.

3. Due to the non-specificity of symptoms of UTI in young children, screening for UTI with urine investigations should be done early, especially in the absence of an obvious source of infection.

4. Urine collected from a urine bag is a useful screening test for UTI in children who have not achieved urinary continence, although it is not a diagnostic test.

5. Urine culture is the gold standard for diagnosis of UTI. If the screening urine bag specimen is suggestive of UTI, urine culture needs to be obtained to confirm the diagnosis. A child who requires intravenous antibiotics should be referred to a tertiary hospital for collection of urine culture (through in-out catheterisation or clean catch).

6. If the child is assessed to be suitable for oral antibiotics, two separate midstream urine samples should be collected in the outpatient setting, with at least one sample collected prior to initiation of antibiotics.

7. Both upper and lower tract UTIs can be treated in the outpatient setting. Lower UTIs require one week of treatment, whereas upper UTIs require 14 days of antibiotics therapy. For upper UTIs, patients who are aged $<6$ months, acutely unwell, unable to tolerate oral therapy or have complicated UTI will need inpatient parenteral antibiotic treatment.

8. Urine cultures should also be traced to ensure targeted antibiotic therapy, and all patients should be reviewed 48-72 hours after initiation of antibiotic therapy to evaluate their response to treatment.

9. Treatment of constipation with stool softeners is effective in preventing recurrent UTI in children without urinary tract abnormalities.

10. Indications for referral to a tertiary hospital are patients who require intravenous antibiotics and those who need further workup. Patients with febrile UTI or recurrent cystitis should be referred for follow-up imaging 4-6 weeks after acute infection. 
A urine bag was placed on Jane. After half an hour, a urine specimen was successfully collected. A dipstick test showed a leucocytes value of 4+ and was positive for nitrites. As Jane was haemodynamically stable, a decision was reached after discussion with her mother for her to undergo outpatient treatment with a course of antibiotics. Jane's mother was instructed to obtain two separate clean-catch urine specimens, which were sent to the laboratory for urinalysis and urine culture. Oral cephalexin was prescribed for 14 days with instructions to start antibiotics only after urine specimens were collected. A follow-up appointment was scheduled for Jane to be reviewed in two days. Urinalysis showed that her urine was pyuric and nitrites were positive. Her urine cultures revealed Escherichia coli with significant growth of $>100,000 \mathrm{cfu} / \mathrm{mL}$, sensitive to cephalexin. On subsequent review, Jane's fever had subsided after 48 hours of antibiotics, and she was back to her usual self. Her mother was advised to complete the whole course of antibiotics. A referral to a paediatric tertiary hospital was made for further investigations and follow-up.

\section{REFERENCES}

1. Millner R, Becknell B. Urinary tract infections. Pediatr Clin North Am 2019; $66: 1-13$.

2. Urinary tract infection in under 16s: diagnosis and management. London: National Institute for Health and Care Excellence (UK); 2018 Oct.

3. Williams G, Craig JC. Long-term antibiotics for preventing recurrent urinary tract infection in children. Cochrane Database Syst Rev 2019; 4:CD001534.

4. Montini G, Tullus K, Hewitt I. Febrile urinary tract infections in children. N Engl J Med 2011; 365:239-50.

5. Montini G, Zucchetta $P$, Tomasi $L$, et al. Value of imaging studies after a first febrile urinary tract infection in young children: data from Italian renal infection study. Pediatrics 2009; 123:e239-46.

6. Shaikh N, Craig JC, Rovers MM, et al. Identification of children and adolescents at risk for renal scarring after a first urinary tract infection: a meta-analysis with individual patient data. JAMA Pediatr 2014; 168:893-900.

7. Subcommittee on Urinary Tract Infection, Steering Committee on Quality Improvement and Management, Roberts KB. Urinary tract infection: clinical practice guideline for the diagnosis and management of the initial UTI in febrile infants and children 2 to 24 months. Pediatrics 2011; 128:595-610.

8. Salo J, Ikäheimo R, Tapiainen T, Uhari M. Childhood urinary tract infections as a cause of chronic kidney disease. Pediatrics 2011; 128:840-7.

9. Downs SM. Technical report: urinary tract infections in febrile infants and young children. The Urinary Tract Subcommittee of the American Academy of Pediatrics Committee on Quality Improvement. Pediatrics 1999; 103:e54.

10. Levtchenko EN, Lahy C, Lévy J, Ham HR, Piepsz A. Role of Tc-99m DMSA scintigraphy in the diagnosis of culture negative pyelonephritis. Pediatr Nephrol 2001; 16:503-6.

11. Shaikh N, Shope TR, Hoberman A, et al. Association between uropathogen and pyuria. Pediatrics 2016; 138:e20160087.

12. Fitzgerald A, Mori R, Lakhanpaul M, Tullus K. Antibiotics for treating lower urinary tract infection in children. Cochrane Database Syst Rev 2012; (8):CD006857.

13. Strohmeier Y, Hodson EM, Willis NS, Webster AC, Craig JC. Antibiotics for acute pyelonephritis in children. Cochrane Database Syst Rev 2014; (7):CD003772.

14. Loening-Baucke $\mathrm{V}$. Urinary incontinence and urinary tract infection and their resolution with treatment of chronic constipation of childhood. Pediatrics 1997; 100(2 Pt 1):228-32.

15. Hellerstein S, Linebarger JS. Voiding dysfunction in pediatric patients. Clin Pediatr (Phila) 2003; 42:43-9.

16. Singh-Grewal D, Macdessi J, Craig J. Circumcision for the prevention of urinary tract infection in boys: a systematic review of randomised trials and observational studies. Arch Dis Child 2005; 90:853-8.

17. Schwenger EM, Tejani AM, Loewen PS. Probiotics for preventing urinary tract infections in adults and children. Cochrane Database Syst Rev 2015; (12):CD008772.

18. Lee BS, Bhuta T, Simpson JM, Craig JC. Methenamine hippurate for preventing urinary tract infections. Cochrane Database Syst Rev 2012; 10:CD003265.

19. Jepson RG, Williams G, Craig JC. Cranberries for preventing urinary tract infections. Cochrane Database Syst Rev 2012; 10:CD001321. 


\section{SINGAPORE MEDICAL COUNCIL CATEGORY 3B CME PROGRAMME} (Code SMJ 202107A)

1. Acute urinary tract infection (UTI) is uncommon in children.

2. Screening for UTI should be done early, especially in the absence of an obvious source of infection.

3. Lower UTI is the most common form of UTI.

4. Fever is a cardinal symptom of upper UTI.

5. Defining the location of the UTI is useful in determining prognosis, treatment and follow-up.

6. Urine culture is the gold standard for diagnosing UTI.

7. A bag specimen should be used for urine culture in children who are not toilet trained.

8. A midstream clean-catch urine specimen should be processed within two hours of collection.

9. Bladder bowel dysfunction is an important risk factor for recurrent UTI in children.

10. A palpable bladder is a red flag in a child with UTI.

11. When using clean-catch midstream urine specimens for urine culture, two separate specimens should be collected.

12. After initiation of antibiotic treatment, patient should be reviewed one week later to assess for response.

13. All patients with one episode of febrile UTI should be referred to a tertiary hospital for further workup.

14. Treatment of constipation is effective in preventing recurrent UTI in children without urinary tract anatomical abnormalities.

15. Routine circumcision should be done in all patients with UTI.

16. Cranberry juice is an evidence-based prophylactic therapy for UTI.

17. A one-month-old baby with febrile UTI can be treated with oral antibiotics if clinically stable.

18. A UTI carries an acute risk of morbidity and mortality.

19. Most UTIs are caused by Escherichia coli and other enteric Gram-negative organisms.

20. One week of oral cephalexin should be prescribed for a six-year-old boy diagnosed with lower UTI.

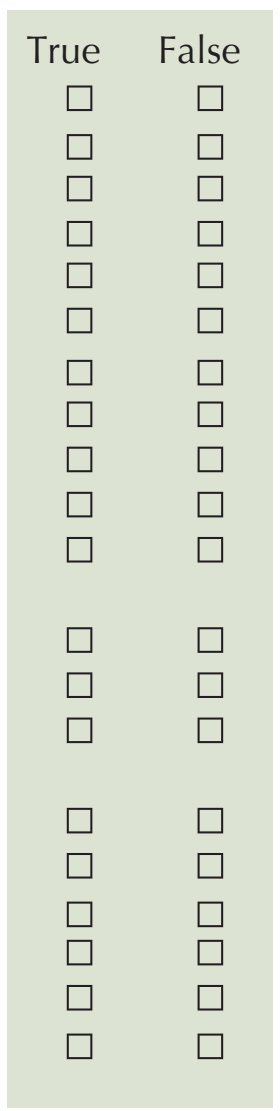

\section{Doctor's particulars:}

Name in full:

MCR no:

Specialty:

Email:

\section{SUBMISSION INSTRUCTIONS}

Visit the SMJ website: http://www.smj.org.sg/current-issue and select the appropriate quiz. You will be redirected to the SMA login page.

For SMA member: (1) Log in with your username and password (if you do not know your password, please click on 'Forgot your password?'). (2) Select your answers for each quiz and click 'Submit'.

For non-SMA member: (1) Create an SMJ CME account or log in with your SMJ CME username and password (for returning users). (2) Make payment of SGD 21.40 (inclusive of $7 \%$ GST) via PayPal to access this month's quizzes. (3) Select your answers for each quiz and click 'Submit'.

RESULTS:

(1) Answers will be published online in the SMJ September 2021 issue. (2) The MCR numbers of successful candidates will be posted online at the SMJ website by 21 September 2021. (3) Passing mark is $60 \%$. No mark will be deducted for incorrect answers. (4) The SMJ editorial office will submit the list of successful candidates to the Singapore Medical Council. (5) One CME point is awarded for successful candidates. (6) SMC credits CME points according to the month of publication of the CME article (i.e. points awarded for a quiz published in the July 2021 issue will be credited for the month of July 2021, even if the deadline is in September 2021).

Deadline for submission (July 2021 SMJ 3B CME programme): 12 noon, 14 September 2021. 